doi: 10.32620/oikit.2021.91.05

УДК 538.95

Ю. В. Широкий,

Г. І. Костюк

\title{
Моделювання дугового розряду на мідному катоді для генерації наноструктур
}

\author{
Національний аерокосмічний університет ім. М. Є. Жуковського \\ «Харківський авіаційний інститут»
}

\begin{abstract}
У роботі розглянуто модель процесів, що діють в іонізаційному шарі катодного вузла при плазмовій генерації наноструктур. У наведеній моделі досить докладно розглянуто процеси в електродинамічному та газодинамічному шарах плазми та їх узгодження. Тому вирішення моделі дозволяє досить адекватно визначити величину катодного стрибку потенціалу в електродинамічному шарі, що дає можливість компенсації всіх енергетичних утрат при генерації наноструктур, та величини потоків іонів та електронів на катоді. Розрахунки виконувались при постійному значенні подовженості іонізаційного шару, оскільки вона мало впливає на змінення густини іонного струму по довжині прикатодних шарів. Також розрахунки підтвердили несуттєву залежність вихідного тиску з іонізаційного шару від температури електронів. Отримані графіки залежності частки іонного струму на катоді та катодного спаду потенціалу від щільності струму при різних температурах катода показали, що змінення частки іонного струму надає можливість компенсації затрат енергії на підтримку температури катода. А розгляд рівняння балансу енергій дозволив визначити діапазон утрат робочого тіла, при якому можна не враховувати енергію на випаровування робочого тіла та підігрівання пари. Для визначення густини струму на катоді було отримано залежність термоемісійного струму від температури катода та залежність густини струму на катоді від концентрації плазми при різних катодних спадах і різних поданнях напруженостей електричного поля. Це дозволило визначити температуру катода через густину іонного струму та оцінити концентрацію плазми. Залежності від концентрації плазми отримано коефіцієнт електропереносу для різних механізмів емісії та катодних спадів. Все це дозволило визначити залежність питомої маси, що залишає катод в одиницю часу з одиниці площі, від температури катода та густини теплового потоку для мідного катода. Визначення питомої маси та коефріцієнта електропереносу надає можливість визначити ресурс катода при плазмовій генерації наноструктур.
\end{abstract}

Ключові слова: нанотехнологія, плазма, катод, іонізаційний шар, газодинамічний шар іонний струм, температура.

\section{1. Вступ}

На цей час $є$ багато робіт, присвячених дослідженню процесів під час плазмово-іонної обробки [1-4] і при отриманні покриттів [3-6], і значно менше, які досліджують процеси під час плазмово-іонної генерації наноструктур. Особливо цікавим $є$ задання частки іонного струму на катоді з урахуванням вибору механізму емісії електронів з поверхні катода. Оскільки більшість досліджень процесів у прикатодному шарі, при генерації наноструктур, розглядалися незалежно від механізму емісії електронів $[5,6]$ та задання частки долі іонного струму [7-9]. Тому є доцільним розглянути задачі для прикатодного шару при плазмово-іонній генерації наноструктур 3 широким колом параметрів, які визначають частку іонного струму та механізм емісії електронів. Розгляд процесів у катодному шарі [10,11] зазвичай проводять у загальних припущеннях, які не накладають обмежень на використання 
залежностей, що описують параметри, тільки у вузькому діапазоні параметрів. Тому загальна постановка прикатодної задачі при генерації наноструктур, дозволить не тільки визначити параметри фрізичного процесу у прикатодній області а також допоможе розкрити характер розподілу параметрів у прикатодному шарі. Вирішення цієї задачі дозволить визначить ресурс катодів під час генерації наноструктур у плазмовому середовищу. Розрахунки будемо проводити для мідних катодів.

\section{1. Теоретичний розгляд процесів}

Деякі процеси у прикатодній зоні при плазмо-іонній генерації вже розглядалися [10-13] але при цьому не враховувались технологічні параметріи при отриманні наноструктур. Тому теоретично розглянемо процеси у прикатодній зоні при генерації наноструктур. Як показано в [12], коли дебаєвський радіус багато менше довжини вільного пробігу зарядженої частинки $\lambda_{D}<<\ell$, розгляд процесів у прикатодному шарі можна розділити на дві задачі (рис. 1) [12,13]: процеси в газодинамічному шарі і процеси в електродинамічному шарі;

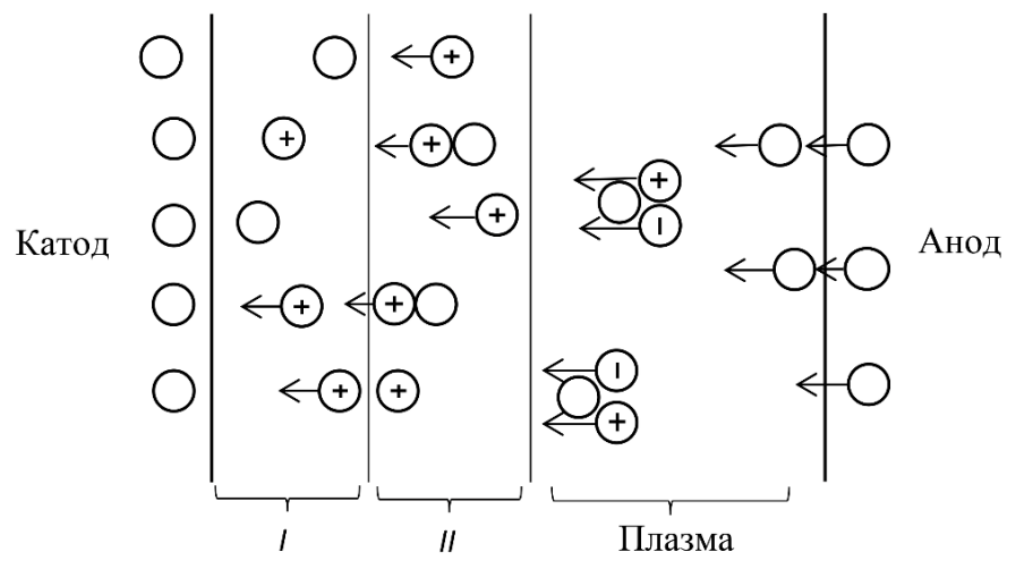

Рис. 1. Схема процесів у прикатодній області розряду I - електродинамічний шар; II - іонізаційний шар

Виходячи з того, що ларморівський радіус для іона $\left(r_{g i}\right)$ значно більше ларморівського радіуса електрона $\left(r_{g e}\right)$, а $\lambda_{D}$ електрона значно більше дебаєвського радіуса екранування, електродинамічний шар можна розглядати як два (рис. 1): беззіштовхувальний шар (зона катодного стрибка потенціалу) і зіштовхувальний (іонізаційний) шар [14].

Для опису процесів у беззіштовхувальній зоні скористаємося рівнянням Пуассона:

$$
\Delta \varphi=\frac{j_{e}}{\varepsilon_{0}} \cdot\left(\frac{1}{V_{e}}-\frac{\beta_{k}}{V_{i}}\right)
$$

та рівнянням руху для електронів

$$
\left(V_{e} \cdot \bar{V}\right) \cdot V_{e}=-e E / m_{e}
$$


з граничними умовами $y=0, \varphi=0, V_{e}=\sqrt{3 T_{e} K / 2 m_{e}}$, а також рівнянням руху для іонів

$$
\left(V_{i} \cdot \bar{V}\right) \cdot V_{i}=-e E / m_{i}
$$

з граничними умовами:

$$
y=d, \varphi=\Delta \varphi, E=E_{i}, V_{i}=\sqrt{3 T_{i} K / 2 m_{i}},
$$

де $\rho_{\kappa}-$ частка іонного струму на катоді;

Ve i $\mathrm{Vi}$ - поперечні швидкості електронів та іонів;

$T_{e}$ - температура електронів у катоді в енергетичних одиницях;

$T_{i}$ - температура іонів на межі 1 (див. рис. 1);

$\Delta \phi$-катодний стрибок потенціалу;

$d$ - товщина електродинамічного шару, що дорівнює дебаєвському радіусу.

Виходячи з того, що у зіштовхувальному шарі (див. рис. 1) електрони стикаються 3 нейтральними компонентами плазми іонізаційного шару прикатодної зони, вони швидко максвелізуються, іонізуя і збуджуючи нейтральні атоми, втрачаючи отриману енергію в зоні катодного стрибка. Тому опис іонізаційного шару можна звести до рівняння Пуассона, рівняння балансу потоків частинок і балансу енергіі:

$$
\begin{gathered}
\frac{\partial}{\partial x_{k}} \cdot E=\frac{\rho_{0}}{\varepsilon_{0}} \\
\frac{\partial}{\partial x_{k}} n_{\alpha} V_{a_{k}}=i_{\alpha}, r_{a}=W_{a} ; \\
\frac{\partial}{\partial x_{k}}\left[\left[\frac{1}{2} n_{\alpha} m_{\alpha}\left(V_{a}\right)^{2}+\frac{5}{2} n_{\alpha} T_{\alpha}\right] V_{a}+Q_{\alpha i k} V_{a i}+q_{a k}\right]=e_{\alpha} n_{\alpha} E_{i} V_{a}+K_{a},
\end{gathered}
$$

де $\alpha$ - компоненти плазми;

e, i, a - електрони, іони і нейтралі відповідно;

$V_{a k}-k$-компонента швидкості частинок сорту в цілому;

$m_{\alpha}, n_{\alpha}, T_{\alpha}$ - маса, концентрація і температура в енергетичних одиницях газу copту $\alpha$;

$i_{\alpha}-$ заряд іона газу сорту $\alpha\left(e_{\alpha}=0\right)$;

$Q_{\text {aik }}$ - потік тепла з теплопровідністю в частинках певного сорту;

$E_{i}-$ напруженість електричного поля біля катода;

$W_{a}$ - фуннкція іонізації рекомбінації (швидкість зростання кількості іонізованих частинок);

$K_{a}$ - член, що враховує втрати і джерела енергії в газі частинок сорту внаслідок зіткнень з частинками інших сортів;

$\rho_{0}$ - густина об'ємного заряду.

Як граничні умови візьмемо такі рівняння:

$$
\left(n_{e} \cdot V_{e}\right)_{1}=\frac{J_{1}}{e}, \frac{m_{e}\left(V_{e}\right)^{2}}{2}=e \cdot \Delta \varphi_{k}, T_{e}=T_{e}
$$


i

$$
\left(n_{e} \cdot V_{e}\right)_{2}=\frac{J_{2}}{e}, T_{e}=T_{e 2}, T_{e 2}>\frac{m V_{12}}{2}
$$

У загальній постановці завдання, сформоване в рівняннях (1) - (5) охоплює практично всі процеси, що відбуваються як у беззіткневому шарі, так і в шарах, де $€$ зіткнення. Сумісне вирішення наведеної вище моделі дозволить визначити величину катодного стрибка потенціалу в електродинамічному шарі для компенсації всіх енергетичних утрат, а також величини потоків іонів і електронів на катоді.

При пошаровому розгляді задачу вирішимо ії в одновимірному випадку, тоді можна виконати лінеаризацію диференціальних рівнянь, де замість похідних взяти змінення величин у шарі, тобто систему диференціальних рівнянь (1) - (5) розв'язати на основі моделі фронтових процесів, відомої 3 теорії горіння. Тоді з рівняння енергії (5) шляхом нескладних перетворень можна отримати вираз для частки іонного струму на катоді:

$$
\begin{gathered}
\rho_{k}=\frac{A_{0} \rho_{p}+\left[m_{e} \cdot\left(V_{e}\right)^{2} / 2+5 / 2 T_{e 2}\right] \cdot W_{e} /\left(1+\rho_{p}\right)+\left(e \cdot \Delta \varphi+5 / 2 T_{e 1}\right) \cdot W_{c} /\left(1+\rho_{p}\right)}{A_{0}-\left[m_{e} \cdot\left(V_{e}\right)^{2} / 2+5 / 2 T_{e 2}\right]}+ \\
+\frac{\left[\frac{e}{j_{e}}\left(Q_{i k} \cdot V_{e}\right)_{12}+q_{e 12}\right] \cdot W_{e} \cdot\left(1-\rho_{p}\right)}{A_{0}-\left[m_{e}\left(V_{e}\right)^{2} / 2+5 / 2 T_{e 2}\right] \cdot W_{e} /\left(1+\rho_{p}\right)},
\end{gathered}
$$

де $A_{0}=\left\langle K_{e}>-<E_{k} \times j_{e k}>-\right.$ різниця між витратами енергії на зіткнення електронів з частинками іншого сорту і джоулевим нагріванням в іонізованому шарі (кутові дужки <> позначають усереднення величини по іонізаційному шару як тут, так і в подальшому); газі;

$$
q_{e 12}=q_{e 2}-q_{e 1}-\text { витрати потужності на теплопровідність в електронному }
$$

$$
\left(Q_{e i k} \cdot V_{e}\right)_{12}=\left(Q_{e i k} \cdot V_{e}\right)_{2}-\left(Q_{e i k} \cdot V_{e}\right)_{1}-\quad \text { витрати потужності внаслідок }
$$
в'язкості;

$\rho_{\kappa}$ - частка іонного струму на межі з газодинамічними шаром.

У загальному виразі (6) при визначенні частки іонного струму можна знехтувати величинами, які не впливають на точність визначення (потужність, затрачену на в'язкість, теплопровідність, змінення потенціальної і кінетичної енергії, а також енергії від джоулева нагріву).

Тоді вираз (6) після перетворень набуває вигляду

$$
\frac{\left(\rho_{k}-\rho_{p}\right)}{\left(1+\rho_{p}\right)}=\frac{e \cdot \Delta \varphi \cdot W_{e}}{K_{e}}
$$

де 


$$
W_{e}=n_{e} \cdot n_{a} \cdot S_{i} \sqrt{\frac{8 k T_{e}}{\pi \cdot m_{e}}}\left[\frac{1}{T_{e}}+2\right] \cdot \exp \left(\frac{I}{T_{e i}}\right),
$$

$S_{i}=c_{i} \times T_{e 2}$ - площа іонізації при лінійній апроксимації залежності площі від енергії частинки;

$$
T_{e i}=\frac{I}{0.875+0.602 \frac{I}{\Delta \varphi}}-\text { температура реакції іонізації; }
$$

I - потенціал іонізації:

$$
K_{e}=W_{e} \cdot I+\sum_{a=1}^{N} W_{e a} \cdot U_{\text {збуд }} .
$$

Тоді швидкість зростання концентрації збуджених атомів рівня $\alpha$ буде

$$
W_{e}=n_{e} \cdot n_{a} \cdot C_{\text {збуд }} T_{e} \cdot \sqrt{\frac{8 k T_{e}}{\pi m_{e}}} \cdot\left[\frac{U_{\text {збуд.a }}}{T_{e 2}}+2\right] \cdot \exp \left(-\frac{U_{\text {збуд.a }}}{T_{\text {ea }}}\right),
$$

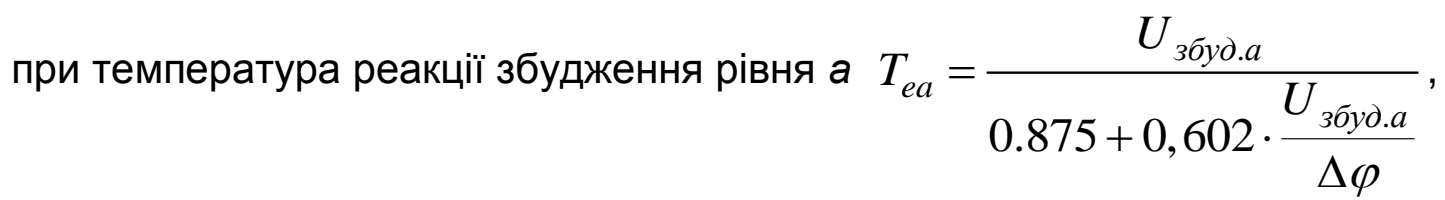

Частку іонного струму на кордоні іонізаційного і газодинамічного шарів, нехтуючи дифузією, можна подати у вигляді

$$
\rho_{p} \leq \frac{\tau_{i 2}}{\tau_{e 2}} \cdot \frac{m_{e}}{m_{i}} \cdot \frac{1+\left(\omega_{e} \cdot \tau_{e 2}\right)^{2}}{1+\left(\omega_{e} \cdot \tau_{i 2}\right)^{2}},
$$

де $t_{e 2}, t_{i 2}$ - час електрон-електронних та іон-іонних зіткнень;

$m_{e}, m_{i}$ - маса електрона та іона;

$w_{e} \times t_{e 2}$ та $w_{e} \times t_{i 2}-$ параметр Холла для електронів та іонів.

Для малих струмів та малих напружень магнітного поля частка іонного струму на правій межі (межі з газодинамічними шаром)

де

$$
\rho_{p} \leq \frac{\tau_{i 2}}{\tau_{e 2}} \cdot \frac{m_{e}}{m_{i}}
$$

$$
\tau_{i 2}{ }^{-1}=\tau_{e i}{ }^{-1}+\tau_{i a}{ }^{-1} \text { та } \tau_{e}^{-1}=\tau_{e i}{ }^{-1}+\tau_{e a}{ }^{-1} .
$$

Час електрон-атомних та іон-атомних зіткнень визначається виразами

$$
\tau_{e a}^{-1}=n_{a} \cdot \sigma_{e a} \cdot V_{e} \text { та } \tau_{i a}^{-1}=n_{a} \cdot \sigma_{i a} \cdot V_{i},
$$

час іон-електронних зіткнень -

$$
\tau_{e i}=\frac{\lambda_{e i} n_{e 2}}{3.5 \cdot 10^{4} \cdot\left(T_{e 2}\right)^{1.5}}
$$


Середню концентрацію нейтрального компонента можна визначити як середню величину між концентраціями на межах і при виконанні умови максвеліалізації нейтралей у шарі маємо

$$
n_{a}=\frac{G}{F_{n p} \cdot m_{a} \sqrt{\frac{8 k T_{a}}{\pi m_{a}}}}
$$

де $G$ - витрата нейтрального компонента через катод;

$F_{n p}$ - площина, по якій рівномірно розподіляється витрата;

$T_{a}$ - температура робочого тіла на виході з катода, яку можна взяти також, що дорівнює температурі катода: $T_{a}=T_{\kappa}$.

Система рівнянь (1) - (2) для беззіштовхувального шару після інтегрування і з урахуванням граничних умов набуде вигляду

$$
E_{k}=\frac{2 \Delta \varphi}{A} \cdot \sqrt{\sqrt{\frac{m_{e}\left(V_{e}\right)^{2}}{2 e \Delta \varphi}+\rho_{k} \sqrt{\frac{m_{i}}{m_{e}}\left[1+\frac{m_{i}\left(V_{i}\right)^{2}}{2 e \Delta \varphi}\right]}}}
$$

де $A^{2}=\frac{\left(1+\rho_{k}\right) \cdot \varepsilon_{0} \cdot \Delta \varphi}{j} \cdot \sqrt{\frac{2 e \Delta \varphi}{m}}, U_{e o}=\sqrt{\frac{3}{2} \cdot \frac{k T_{e o}}{m_{e}}}, U_{i 1}=\sqrt{\frac{3}{2} \cdot \frac{k T_{i 1}}{m_{i}}}$.

Температуру іонів на межі іонізаційного і беззіштовхувального шарів візьмемо такою, що дорівнює температурі атомів: $T_{i}=T$. Баланс частинок в іонізаційному шарі (5) дозволяє отримати вираз для товщини іонізаційного шару $n_{a 2}-\Delta \phi$, необхідну для визначення концентрації нейтральних частинок на кордоні з газодинамічними шаром

$$
n_{a 2}=\frac{G}{D_{a} \cdot m_{a} \cdot F_{n p} \cdot \alpha} \exp (-a \cdot \Delta \varphi)
$$

де $\Delta \varphi=\frac{\left(\rho_{k}-\rho_{p}\right) \cdot \frac{j}{e}}{\left(1+\rho_{p}\right) \cdot\left(1+\rho_{k}\right) \cdot W_{e}}-$ товщина іонізаційного шару, визначена 3 рівняння (18);

$$
a=\sqrt{\frac{\left[n_{e} \cdot S_{i} \cdot \sqrt{\frac{8 k T_{e}}{\pi m_{e}} \cdot\left(\frac{1}{T_{e i}}+2\right)}\right]_{2} \cdot \exp \left(-\frac{1}{T_{e i}}\right)}{D_{a}}},
$$

де $D_{a}-$ коефріцієнт дифузії, який визначається виразом: $D_{a}=\lambda \cdot V_{a} / 3$, а $V_{a}-$ швидкість максвелізованих атомів робочого тіла визначаємо так: $V_{a}=\sqrt{\frac{8 k T_{a}}{\pi m_{a}}}$. Також $\lambda$ - найменша довжина вільного пробігу по відношенню електрон-атомних 
та іон-атомних зіткнень: $\lambda=1 / n \sigma$, де $n$ - середня концентрація відповідного сорту частинок, $\sigma$ - переріз відносно до відповідного виду зіткнень.

Для замикання системи рівнянь (3) - (5) скористаємося рівнянням балансу енергії на катоді:

$$
F_{\text {вип }}-\varepsilon \cdot \sigma_{И} \cdot\left(T_{k}\right)^{4}+\frac{j}{1+\rho_{k}} \cdot\left[\Phi-\rho_{k}\left(\Delta \varphi_{k}+1-\Phi_{i}+\sqrt{e \cdot E}\right)\right],
$$

де $F$ - густина теплового потоку, що відводиться з випаровуваними атомами 3 катода;

$j-$ повний струм на катоді;

$\varepsilon-$ ступінь чорноти матеріалу катода;

$Ф$ і $\Phi_{i}$ - робота виходу електрона з матеріалу катода і робочого тіла.

При малих витратах робочого тіла розглядається баланс енергії на катоді, яких цілком задовільно описує джерела і витрати енергії. При збільшенні витрати енергії з випарника і підігрівання пароподібної фази до температури катода збільшуються і можуть перевищувати в багато разів відведення енергії випромінюванням і відведенням енергії з електронами.

Тоді баланс енергії можна подати так

$$
\begin{aligned}
& \varepsilon \cdot \sigma_{u} \cdot\left(T_{k}\right)^{4}+\frac{G}{F_{n p}}\left[\lambda_{\text {вип }}+\left(T-T_{\text {вun }}\right) \cdot c_{p}\right]+ \\
& +\frac{j}{1+\beta_{k}}\left[\Phi-\rho_{k}\left(\Delta \varphi_{k}+I-\Phi_{i}+\sqrt{e \cdot E}\right)\right]=0,
\end{aligned}
$$

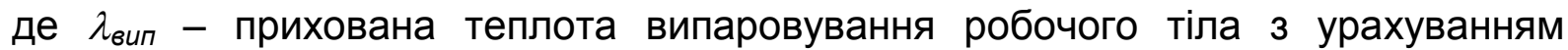
підігріву робочого тіла від температури плавлення до температури випаровування;

$T_{\text {вип }}$ - температура кипіння робочого тіла;

$C_{p}$ - теплоємність пари, що підігрівається.

Розрахунки проводилися для першого і другого варіантів завдання балансу енергії на катоді. З'єднання газодинамічного завдань та електродинамічного можлива за величиною тиску на межі між ними. Тоді тиск на межі з боку іонізаційного шару можна подати так:

$$
P_{2}=\sum_{a} n_{a} T_{a}=k\left[n_{e 2}\left(T_{e 2}+T\right)+n_{a 2} T\right],
$$

де $\mathrm{n}_{\mathrm{e} 2}-$ концентрація електронів на межі.

\section{2. Результати розрахунків}

Розрахунки за наведеною вище моделлю виконувались для випадку генерування наноструктур при дуговому розряді на мідному катоді При обчислення варіювалися такі параметри: температура катода - в діапазоні 2500...3500 К, витрата робочого тіла - в діапазоні $10^{-3} \ldots 10^{-6}$ кг / с. Постійною вважалась електронна температура емітованих електронів, ії величина за експериментальними даними [17] становила $\mathrm{Ti}=2 \mathrm{eB}$.

Як показали розрахунки, протяжність іонізаційного шару при різних значеннях величини $\Delta \phi$ мало впливає на змінення густини електронного та іонного струму по довжині шарів (як зіштовхувального так і 
беззіштовхувального) та майже не впливає на концентрацію нейтральних частинок. Тому в подальшому розрахунки здійснювалися при постійній величині протяжності іонізаційного шару. Також розрахунки підтвердили $[15,17]$ несуттєву залежність вихідного тиску з іонізаційного шару від величини температури електронів, що підвищує вимоги до значень електронної температури на катоді.

При використанні рівняння енергетичного балансу без урахування витрат енергії на випаровування та підігрівання робочого тіла не спостерігається залежності величини катодного спаду потенціалу від витрати робочого тіла. Але згідно з розрахунками частка іонного струму (рис. 2) і катодного спаду потенціалу (рис. 3) залежать від температури катода і густини струму на катоді (рис. 2). Також з отриманих залежностей видно, що при малих густині струму і катодного спаду потенціалу збільшується підігрів катода до заданої температури, причому з урахуванням охолодження катода випромінюванням завдяки емісії електронів. Причому частка іонного струму також збільшується (рис. 2). Все це приводить до компенсації витрат енергії на підтримку температури катода.

Урахування витрат енергії на випаровування робочого тіла і підігрівання пари (21) дозволяє визначити діапазон витрат робочого тіла, при якому можна не враховувати цю енергію. Як зазначалося раніше, залежність величини катодного падіння від витрати робочого тіла не спостерігалося при використанні рівнянь (3) - (5), на рис. 3 - штрихова лінія. Але при урахуванні енергії, пов'язаної з підігріванням і випаровуванням робочого тіла, величина катодного спаду вже істотно змінюється з витратою робочого тіла $10 \mathrm{\kappa г/c,} \mathrm{а} \mathrm{при} \mathrm{великих}$ витратах напевно обов'язково необхідно проводити облік цієї енергії, інакше всі величини, а особливо величина тиску на межі з газодинамічними шаром, будуть суттєво знижені. Тому дані, наведені для високих витрат робочого тіла, потребують перевірки.

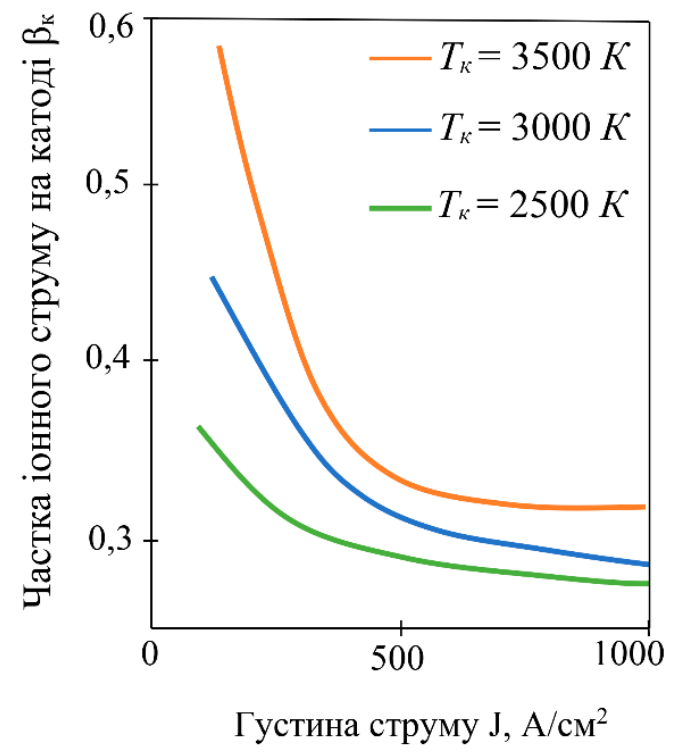

Рис. 2. Графрік залежності частки іонного струму на катоді від щільності струму для різних температур катода

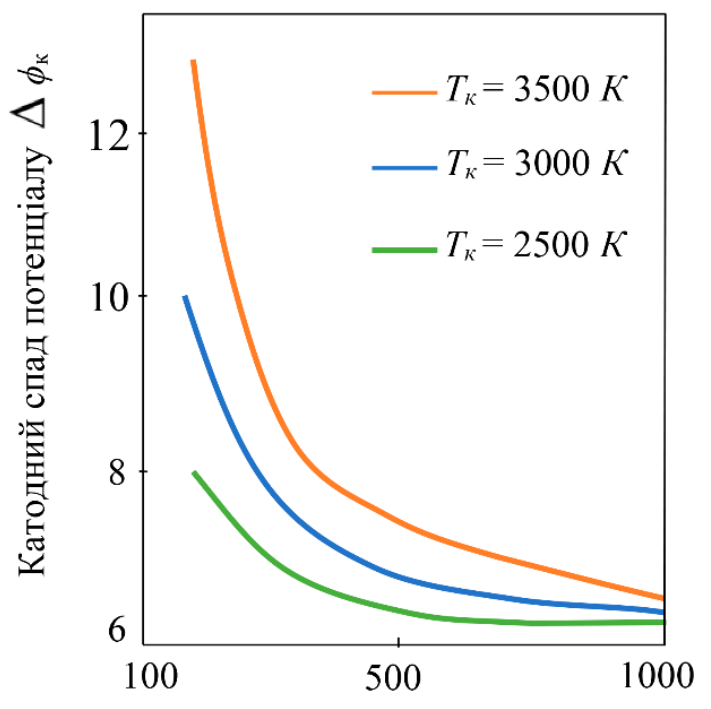

Густина струму $J, \mathrm{~A} / \mathrm{cm}^{2}$

Рис. 3. Катодний спад потенціалу в залежно від густини струму для різних температур катода 
Визначення можливої густини струму на катоді розглядалось 3 урахуванням термоелектронного механізму емісії і залежності густини іонного струму від температури (рис. 4).

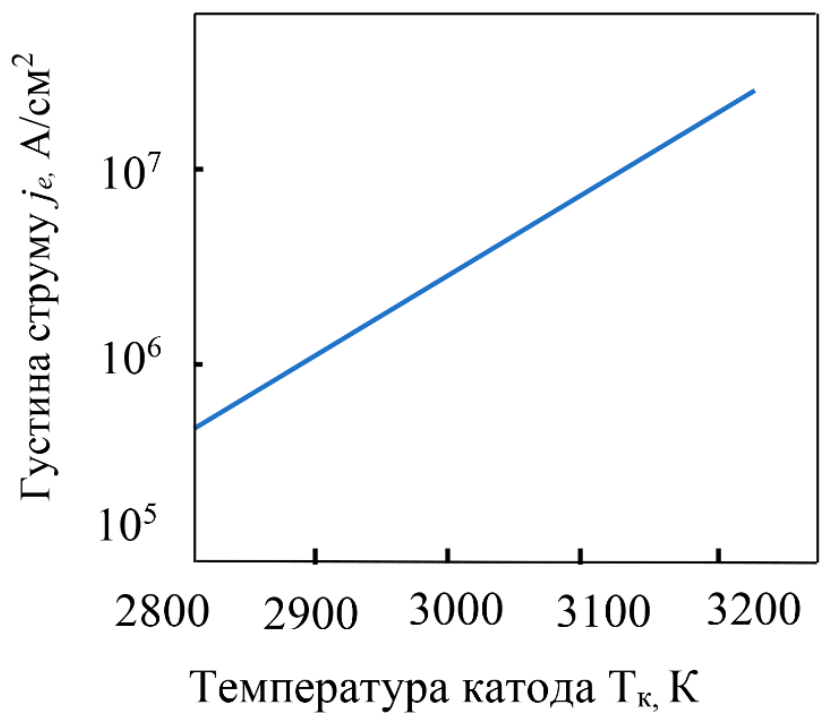

Рис. 4. Графрік залежності густини термоемісійного струму је від температури катода при $\Delta \varphi_{\kappa}=10$ В

Також для різних катодних спадів ( $\left.\mathrm{a}-\bigcup_{\mathrm{k}}=10 \mathrm{~B}, \sigma-\bigcup_{\mathrm{k}}=100 \mathrm{~B}\right)$ подано графріки залежності густини струму на катоді від концентрації плазми в іонізаційному шарі (рис. 5), причому як при термоавтоелектронній емісії МерфріГіда $\left(E_{k}=U / d\right)$ так і з урахуванням індивідуальних полів іонів $\left(\mathrm{E}_{\mathrm{k}}=\mathrm{f}\left(\mathrm{U}_{\mathrm{k}}\right)^{3 / 4}\right)$.

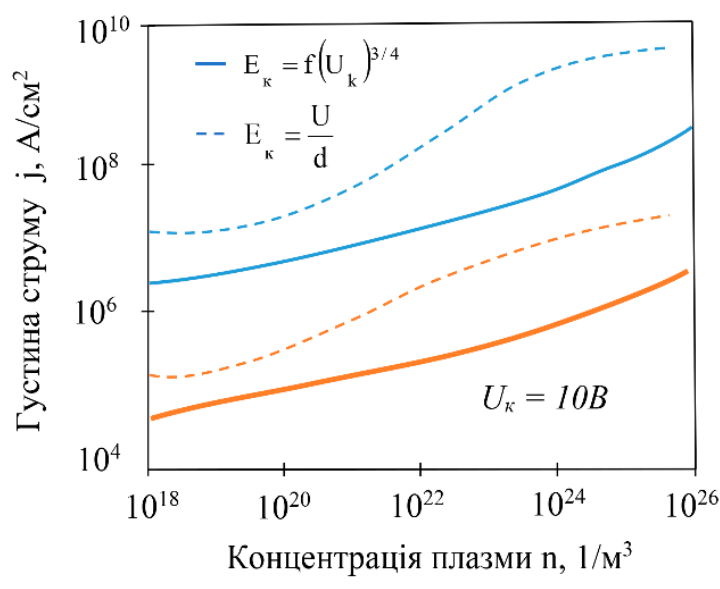

a

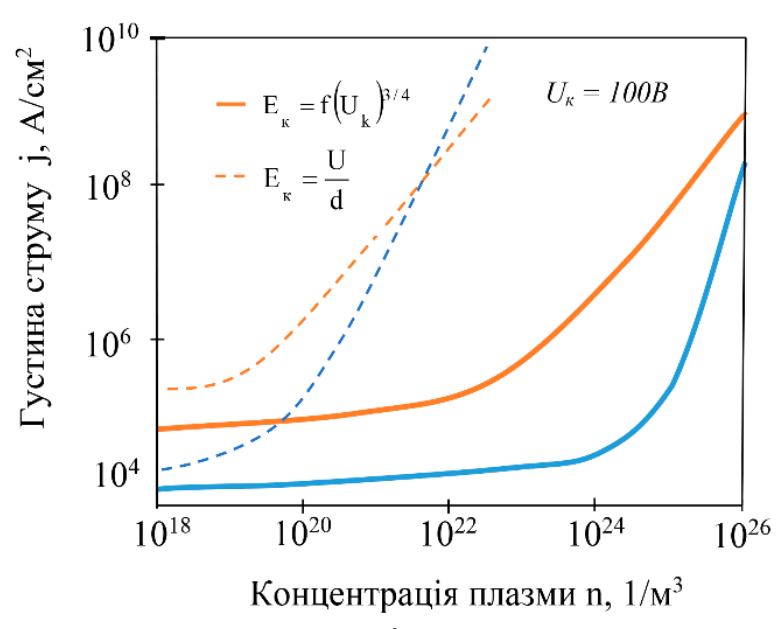

6

Рис. 5. Графрік залежності величини густини струму на катоді від концентрації плазми для різних катодних спадів $\bigcup_{\kappa}$ і різних випадків подання напруженості електричного поля $\mathrm{E}_{\mathrm{K}}$ і механізмів емісії

Ці залежності дозволяють визначити можливий механізм емісії електронів з катода. Також значення тиску, отримані з рівняння балансу енергії (16) залежно від температури катода, дозволяє замкнути систему рівнянь на межі іонізаційного і газодинамічного шарів за однаковим тиском на виході 3 
іонізаційного шару (рис. 6) та на вході в газодинамічний шар (рис. 7) при густині струму j $=10^{6} \mathrm{~A} / \mathrm{cm}^{2}$.

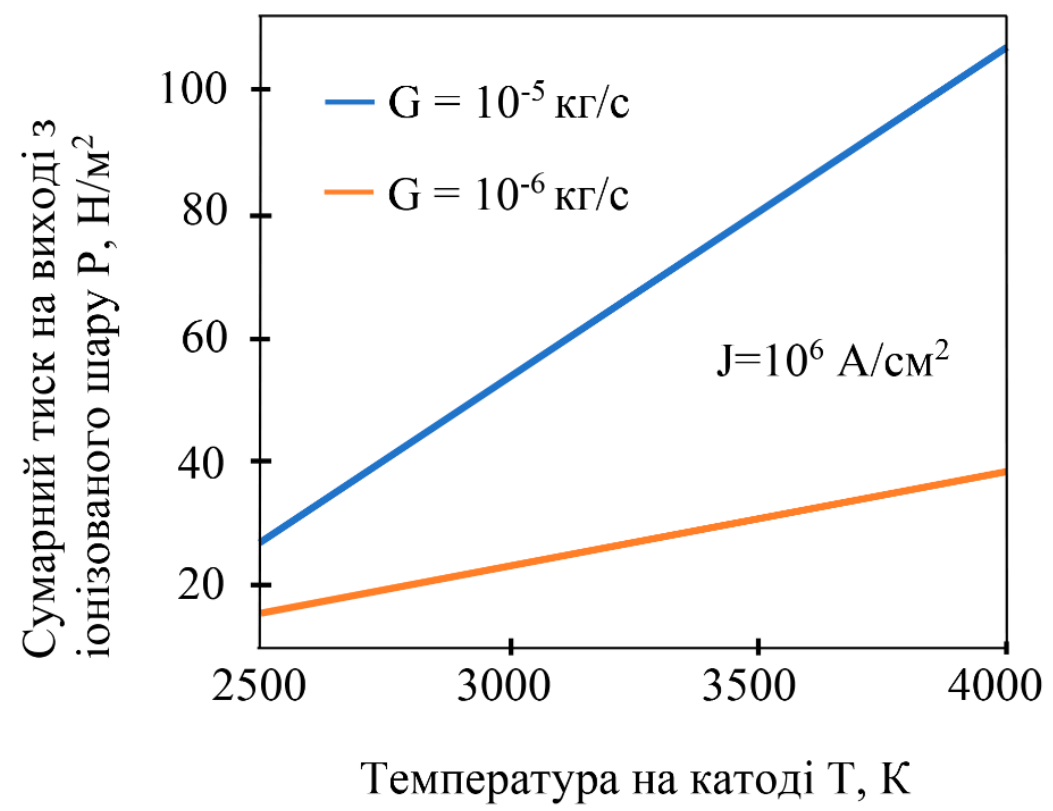

Рис. 6. Графрік залежності сумарного тиску на виході з іонізаційного шару від температури катода для густини струму $\mathrm{j}=10^{6} \mathrm{~A} / \mathrm{cm}^{2}$ та різних витрат газу $\mathrm{G}$

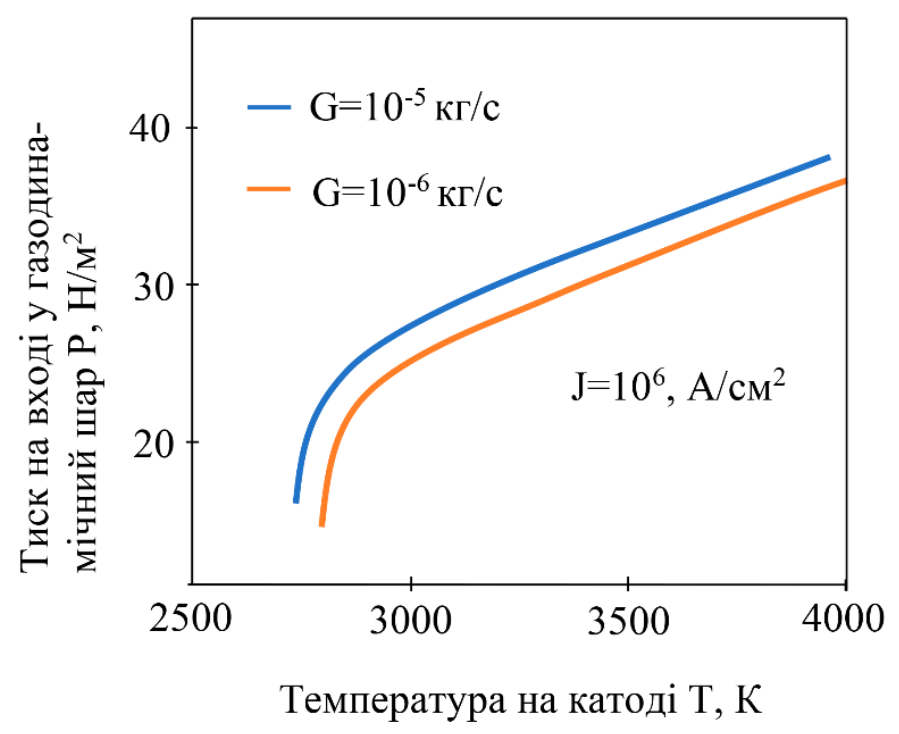

Рис. 7. Графрік залежності газодинамічного тиску на вході у газодинамічний шар від температури катода для густини струму $\mathrm{j}=10^{6} \mathrm{~A} / \mathrm{cm}^{2}$ та витрат газу $\mathrm{G}$

Завдяки зазначеному вище можна визначити температуру катода за густиною іонного струму, оцінити концентрацію плазми та 3 урахуванням характеру розподілу магнітного поля по довжині іонізаційного шару отримати напруженість електричного поля та потенціал плазми при отриманні наноструктур. У свою чергу залежно від концентрації плазми отримано 
коефіцієнт електропереносу для різних механізмів емісії та катодних спадів (рис. 8). 3 урахуванням величини температури катода або густини теплового потоку визначено питому масу, що видаляється 3 катода в одиницю часу 3 одиничної площі W (рис. 9 і 10).

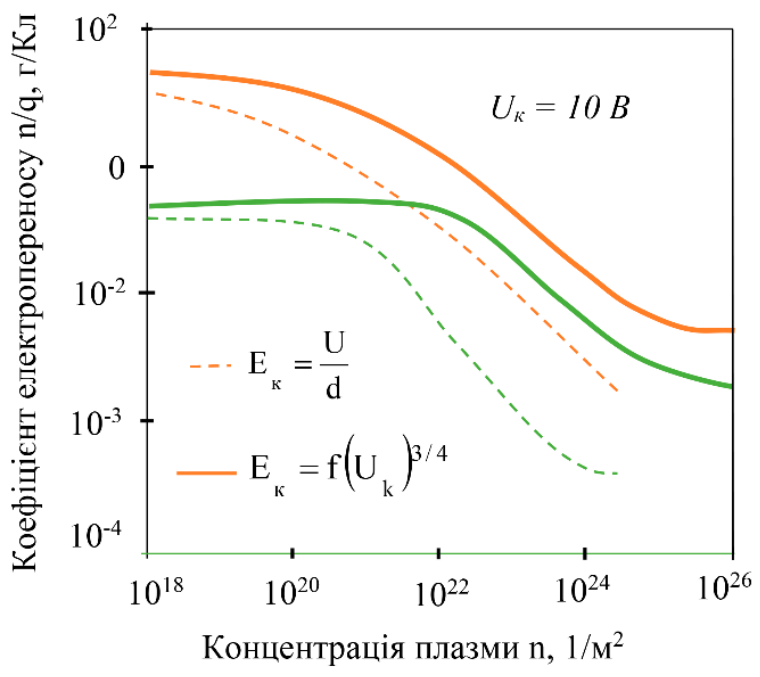

a

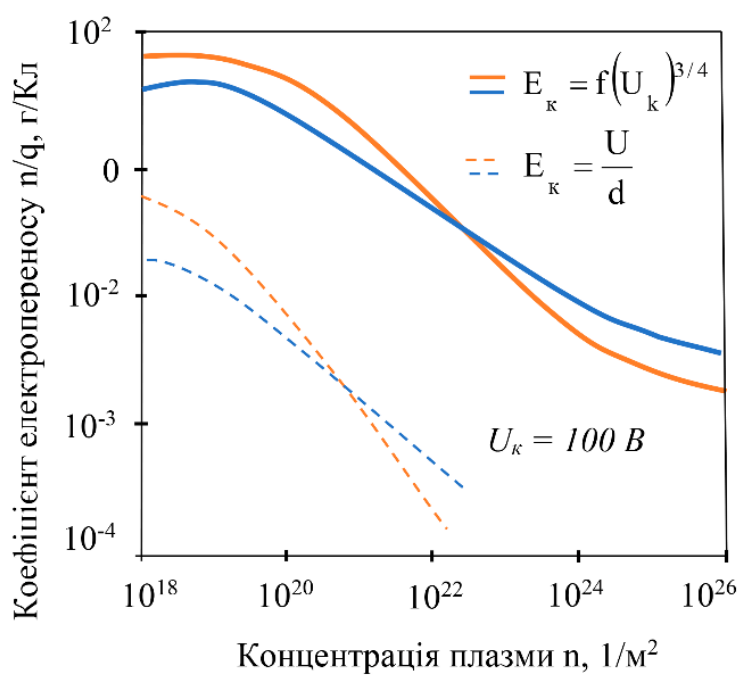

6

Рис. 8. Графрік залежності величини коефріцієнта електропереносу від концентрації плазми для різних катодних спадів $\bigcup_{\kappa}$, різних випадків подання напруженості електричного поля $\mathrm{E}_{\kappa}$

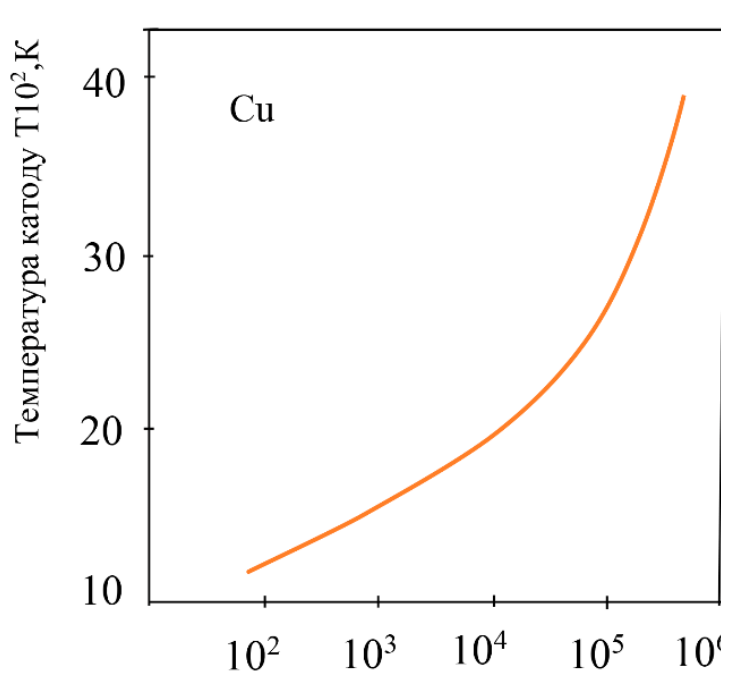

Питома маса що залишає катод $\mathrm{W}, \Gamma / \mathrm{cm}^{3} \mathrm{c}$

Рис. 9. Графрік залежності питомої маси, що виділяється з мідного катода, від його температури

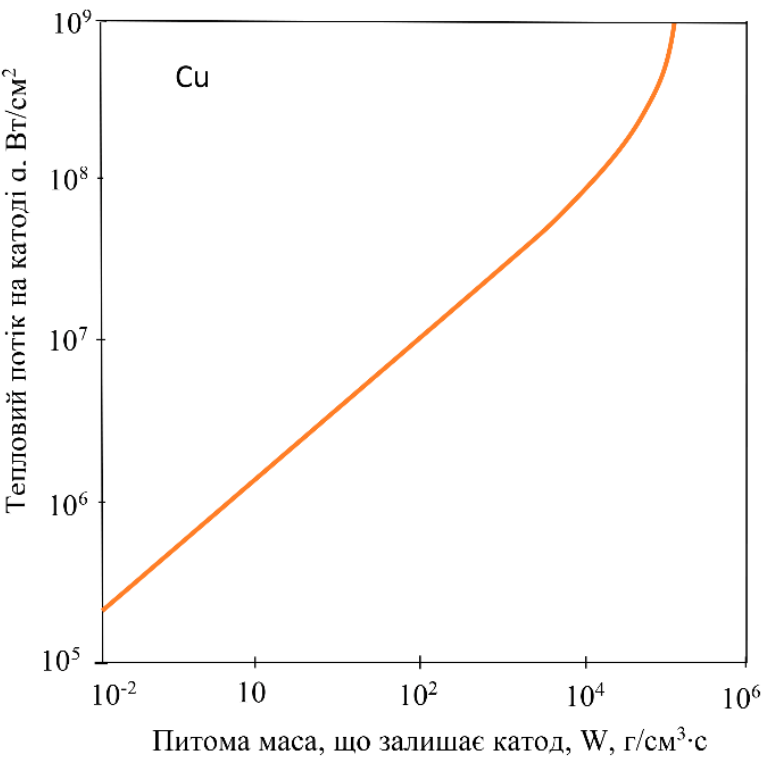

Рис. 10. Графрік залежності питомої маси, що виділяється з мідного катода, від теплового потоку на катоді

Усе зазначене вище дозволяє отримати ресурс катодного вузла технологічного плазмового пристрою при генеруванні наноструктур, а також 
визначити механізм емісії та напруженість електричного потенціалу плазми по довжині, тиск на межі іонізаційного і газодинамічного шарів та оцінити ефективність генерації частинок з катода.

\section{Висновки}

Докладно було розглянуто модель процесів, що діють у іонізаційному шарі катодного вузла при генерації наноструктур. Завдяки цьому розраховано частку іонного струму на катоді 3 міді та знайдено його температуру. Впорядкованість процесів моделі дозволяє з'ясувати величину катодного спаду, оцінити характер розподілу концентрації електронів та потенціалу плазми. Досліджено ефективності генерації часток з катода з метою подальшої оцінки його ресурсу.

\section{Подяки}

Автор висловлює подяку Національному фонду досліджень України за підтримку (конкурс «Підтримка досліджень провідних та молодих учених», номер проекту 2020.02/0119).

\section{Список літератури}

1. Beilis, I. I. Cu film deposition using a vacuum arc with a black-body electrode assembly / I. I. Beilis, Y. Koulik, R. L. Boxman // Surface and Coatings Technology. - 2014. - № 258. - P. 908-912.

2. Takikawa, H. Review of Cathodic Arc Deposition for Preparing DropletFree Thin Films / H. Takikawa and H. Tanoue // Transactions on Plasma Science, 2007. - № 35. - P. 992-999.

3. Schultrich B. Methods of Vacuum Arc Deposition of ta-C Films. I Schultrich B // In: Tetrahedrally Bonded Amorphous Carbon Films I. Springer Series. in Materials Science. - Berlin 2018. - № 263.- P. 721-738.

4. Vorob'ev, V. Plasma arising during the interaction of laser radiation with solids. / V. Vorob'ev // Physics-Uspekhi. - 2007. - № 36. - P. 1129.

5. Beilis, I. Application of vacuum arc cathode spot model to graphite cathode / I. Beilis // IEEE Transactions on Plasma Science. - 1999. - № 27. P. 821-826.

6. Karpov, D. A. Cathodic arc sources and macroparticle filtering. I D.A.Karpov // Surface and Coatings Technology. - 1997. - № 96. - P. 22-33,

7. Beilis, I. Electrode Erosion. Macroparticle Generation. In: Plasma and Spot Phenomena in Electrical Arcs / I. Beilis //Springer Series on Atomic, Optical, and Plasma Physics. - 2020. - № 113. - Springer, Cham.

8. On the growth and electrical characterization of $\mathrm{CuO}$ nanowires by thermal oxidation / K. Bazaka, O. Baranov, U. Cvelbar, B. Podgornik, Y. Wang, S.Huang, L. Xu, J. W. M. Lim, I. Levchenko, S. Xu // Nanoscale. - 2018. - № 10. P. 17494-1751.

9. Plasma under control: advanced solutions and perspectives for plasma flux management in material treatment and nanosynthesis / O. Baranov, K. Bazaka, H.Kersten, M. Keidar, U. Cvelbar, S. Xu, I. Levchenko // Applied Physics Reviews. 2017. - № 4. - P. 041302.

10. Keidar, M. Macroparticle interaction with a substrate in cathodic vacuum arc deposition. / M. Keidar, I. Beilis, R. L., Boxman\& S. Goldsmith// Surface \& Coatings Technology. - 1996. - № 86(87). - P 415-420. 
11. Острецов, И.Н. Об уравнении термоэлектронной эмиссии в плазму. / И. Н. Острецов, В. А. Петросов, А. А. Поротников, Б. Б. Родневич // ПМТФ. 1972. - № 3. - С. 17-28.

12. Сысоев Ю. А. Проблемы ионно-плазменных технологий на основе вакуумно-дугового разряда и пути их решения / Ю. А. Сысоев // Авиационнокосмическая техника и технология. -2011 . - № 7. - С. 38-43.

13. Белан, Н. В. Физические основы стойкости электродов плазменных ускорителей и технологических плазменных устройств / Н. В. Белан, Г. И. Костюк, Е. П. Мышелов // Харьков. - 1986. - С. 205.

14. Костюк, Г. И. Исследование влияния энергии ионов, их сорта и заряда на величину объема наноструктуры и эфффективной плотности тока для получения наноструктур / Г. И. Костюк, Е. Г. Костюк, Л. В. Лобанова // Вестник Нац. техн. ун-та "ХПИ" : сб. науч. тр. Темат. вып. : Технологии в машиностроении. - Харьков: НТУ "ХПИ". - 2012. - № 53 (959). - С. 165-174.

15. Костюк, Г.И. Особенности теоретического рассмотрения процессов в электродных пятнах вакуумного разряда /Г. И. Костюк, Ю. В. Широкий, А.Н.Костюк // Открытые информационные и компьютерные технологии. - 2013. - № 60. - C 128-141.

16. Костюк Г.И. Физико-технические основы напыления покрытий, ионной имплантации и ионного легирования, лазерной обработки и упрочнения, комбинированных технологий / Г.И. Костюк // Киев: Изд-во АИНУ. - 2002. C. 1030.

17. Костюк, Г. И. Параметры катодных и анодных пятен в технологических плазменных устройствах (эксперимент) / Г. И. Костюк, Ю. В. Широкий, А. Н. Костюк, И. В. Леонова // Открытые информационные и компьютерные технологии. - 2013. - № 60. - С. 155-164.

\section{References}

1. Beilis, I.I. Cu film deposition using a vacuum arc with a black-body electrode assembly, I. I. Beilis, Y. Koulik, R. L. Boxman [Surface and Coatings Technology], 2014. no 258, pp. 908-912.

2. Takikawa H. Review of Cathodic Arc Deposition for Preparing DropletFree Thin Films / H. Takikawa and H. Tanoue [Transactions on Plasma Science], 2007. no 35, pp. 992-999.

3. Schultrich B. Methods of Vacuum Arc Deposition of ta-C Films. I Schultrich B. [ In: Tetrahedrally Bonded Amorphous Carbon Films I. Springer Series in Materials Science.], Berlin 2018, no 263, pp. 721-738.

4. Vorob'ev, V. Plasma arising during the interaction of laser radiation with solids. [Physics-Uspekhi]. 2007, no 36, p.1129.

5. Beilis I., Application of vacuum arc cathode spot model to graphite cathode, / I. Beilis // IEEE Transactions on Plasma Science. 1999, no 27. pp. 821 826.

6. Karpov, D. A. Cathodic arc sources and macroparticle filtering. I D.A.Karpov [Surface and Coatings Technology], 1997, no 96, pp. 22-33,

7. Beilis I. Electrode Erosion. Macroparticle Generation. In: Plasma and Spot Phenomena in Electrical Arcs. [Springer Series on Atomic, Optical, and Plasma Physics.] 2020, no 113. Springer, Cham.

8. On the growth and electrical characterization of $\mathrm{CuO}$ nanowires by thermal oxidation. K. Bazaka, O. Baranov, U. Cvelbar, B. Podgornik, Y. Wang, S.Huang, L. Xu, J. W. M. Lim, I. Levchenko, S. Xu. [ Nanoscale]. 2018, no 10, pp $17494-1751$. 
9. Plasma under control: advanced solutions and perspectives for plasma flux management in material treatment and nanosynthesis. O. Baranov, K. Bazaka, H.Kersten, M. Keidar, U. Cvelbar, S. Xu, I. Levchenko [Applied Physics Reviews]. 2017. no 4. p. 041302.

10. Keidar, M. Macroparticle interaction with a substrate in cathodic vacuum arc deposition. / M. Keidar, I. Beilis, R. L., Boxman \& S. Goldsmith [Surface \& Coatings Technology]. 1996, no 86(87), pp. 415-420.

11. Ostreczov Y.N., Oburavnenyy termoэlektronnoj эmyssyy $v$ plazmu. Ostreczov. Y`. N., Petrosov V.A., Porotny`kov A.A., Rodnevy`ch B.B. PMTF. 1972. no 3, pp. 17-28. (In Russian).

12. Sыsoev Yu. A. Problemb yonno-plazmennыx texnologyj na osnove vakuumno-dugovogo razryada y` puty` yx reshenyya / Yu. A. Susoev [Avyacyonnokosmycheskaya texnyka y` texnologyya.] 2011, no 7, pp. 38-43. (In Russian)

13. Belan N.V. Fyzycheskye osnovы stojkosty эlektrodov plazmennыx uskorytelej y texnologycheskyx plazmennыx ustrojstv. Belan N.V., Kostyuk G. Y., Mushelov E.P., Xarkov, 1986, p. 205. (In Russian)

14. Kostyuk G. Y: Yssledovanye vlyyanyya эnergy yonov, yx sorta $y$ zaryada na velychy obъema nanostrukturb $y^{\prime}$ эffektyvnoj plotnosty toka dlya poluchenyya nanostruktur G. Y'. Kostyuk, E. G. Kostyuk, L. V. Lobanova [Vestnyk Nacyonalnogo texnycheskogo unyversyteta "XPY"»: sbornyk nauchnih trudov Temat. vsp. : Texnologyy v mashynostroenyy. -"]. Xarkov: NTU "XPY", 2012, no 53 (959), pp. 165-174. (In Russian).

15. Kostyuk G. Y'. Osobennosty teoretycheskogo rassmotrenyya processov $v$ эlektrodnых pyatnax vakuumnogo razryada /G. Y. Kostyuk, Yu.V. Shyroky], A.N. Kostyuk [ Otkrыtыe ynformacyonnыey` kompyuternыe texnology`y], 2013, no 60, pp 128-141. (In Russian).

16. Kostyuk G.Y. Fyzyko-texnycheskye osnovы napыlenyya pokrbtyj, yonnoj ymplantacyy 'y yonnogo legyrovanyya, lazernoj obrabotky 'y uprochnenyya, kombynyrovannыx texnologyj. [Yzdatelstvo AYNU], Kiyv. 2002, p/1030. (In Russian).

17. Kostyuk G. Y. Parametru katodnыx $y^{\prime}$ anodnыx pyaten $v$ texnologycheskyx plazmennыx ustrojstvax (эkspery`ment) /G. Y'. Kostyuk, Yu.V. Shy roky j, A.N. Kostyuk, Y. V. Leonova [Otkrbtbe y`nformacyonnbe y` kompyuternbe texnologyy], 2013, no 60, pp.155-164. (In Russian).

\section{Simulation of an arc discharge on a copper cathode for the generation of nanostructures}

The paper considers the model of processes acting in the ionization layer of the cathode assembly during plasma generation of nanostructures. In the given model the processes in electrodynamic and gas - dynamic layers of plasma and their coordination are rather densely considered. Therefore, the solution of the model allows to adequately determine the magnitude of the cathode potential jump in the electrodynamic layer, which allows to compensate for all energy losses during the generation of nanostructures, and the magnitude of ion and electron fluxes at the cathode. The calculations were performed at a constant value of the elongation of the ionization layer, because it has little effect on the change in the ion current density along the length of the cathode layers. Also, the calculations confirmed a nonsignificant dependence of the initial pressure from the ionization layer on the temperature of the electrons. The obtained dependences, the fraction of ionic current at the cathode and the cathode potential drop from the current density at different cathode temperatures, showed that the change in the proportion of ionic current 
makes it possible to compensate for energy costs to maintain the cathode temperature. And consideration of the equation of energy balance allowed to establish the range of losses of the working fluid at which it is possible not to take into account the energy of evaporation of the working fluid and steam heating. To determine the current density at the cathode, the dependence of the thermoemission current on the cathode temperature and the dependence of the current density on the cathode on the plasma concentration at different cathode drops and different representations of electric field strengths were obtained. This allowed to determine the cathode temperature due to the ionic current density and to estimate the plasma concentration. Depending on the plasma concentration, the electric transfer coefficient for different emission mechanisms and cathode drops is obtained. All this allowed us to determine the dependence of the specific gravity leaving the cathode per unit time per unit area, on the cathode temperature and heat flux density for the copper cathode. Determining the specific gravity and the transfer coefficient makes it possible to determine the life of the cathode during plasma generation of nanostructures.

Key words: nanotechnology, plasma, cathode, ionization layer, gas - dynamic ion current layer, temperature.

\section{Відомості про авторів:}

\section{Сведения об авторах:}

Широкий Юрій Вячеславович - кандидат технічних наук, доцент, кафедри теоретичної механіки, машинознавства та роботомеханічних систем, Національний аерокосмічний університет ім. М. Є. Жуковського «Харківський авіаційний інститут» м. Харків, Україна; i.shyrokyi@khai.edu; ORCID: 0000-00024713-0334

Костюк Геннадій Ігорович - доктор технічних наук, професор, кафедри теоретичної механіки, машинознавства та роботомеханічних систем, Національний аерокосмічний університет ім. М. Є. Жуковського «Харківський авіаційний інститут» м. Харків, Україна; g.kostyuk@khai.edu; ORCID: 0000-00027584-2240

\section{About the Authors:}

Shyrokyi Yurii Vyacheslavovich - Doctor of Philosophy, AssistantProfessor, Head of Department of Theoretical Mechanics, Engineering and Robomechanical Systems, National Aerospace University "Kharkiv Aviation Institute", Kharkiv, Ukraine; i.shyrokyi@khai.edu; ORCID: 0000-0002-4713-0334

Kostyuk Gennady Igorevich - Doctor of Technical Sciences, Professor, Head of Department of Theoretical Mechanics, Engineering and Robomechanical Systems, National Aerospace University "Kharkiv Aviation Institute", Kharkiv, Ukraine; O g.kostyuk@khai.edu; ORCID: 0000-0002-7584-2240 